\title{
Sensing System for Intra-Abdominal Pressure Measurement
}

\section{Teodor Tóth, Monika Michalíková, Jozef Živčák}

Technical University of Košice, Faculty of Mechanical Engineering, Department of biomedical engineering and measurement, Letná 9, Košice, 04200 Slovakia teodor.toth@tuke.sk; monika.michalikova@tuke.sk; jozef.zivcak@tuke.sk

\section{Richard Raši}

Louis Pasteur University Hospital, Rastislavova 43, Košice, 04001 Slovakia rasi@unlp.sk

Abstract: The development of technology and information technology offers new possibilities for detecting intra-abdominal pressure (IAP) in critically ill patients. Presently, non-invasive measuring through the monitoring of pressure in the bladder has begun to be promoted. Studies on monitoring pressure in the urinary tract point to a high level of correlation with pressure in the abdominal cavity. These measures are currently conducted in the majority of workplaces by manual measurement in specified time intervals. In this article the verification of a monitoring system for measuring IAP is described, which is part of a proposed system for automatisation of IAP detection.

Keywords: intra-abdominal pressure; measurement; sensors

\section{Reasons for the Origin of IAH}

The reasons for the origin of inter-abdominal hypertension can be divided into a number of groups based on the aetiology of origin:

1. post-traumatic - the reason for origin is a traumatic mechanism with subsequent damage to individual organs: massive multi-organ disabling, burning, intra-abdominal or retroperitoneal bleeding (a traumatic rupture of the aorta, bleeding from the spleen), massive contusion of the body (antishock trousers), swelling of tissues after a massive intake of fluids during resuscitation, [12] 
2. on the basis of disease and disease complications - infection of the abdominal cavity (stercoraceus or biliary peritonitis), a place of abscess, acute pancreatitis, decompensation cirrhosis with ascites, edema and ascites after a massive intake of fluids, hemoperitoneum or hemoretroperitoneum, [12]

3. as a response to therapeutic procedures - peritoneal dialysis, artificial lung ventilation [12]

4. surgical procedures and their complications - laparoscopic surgery with enforced creation of pneumoperitonea, a large stomach operation, diaphragmatic hernia, application of an abdominal belt after an operation, post-operative bleeding, closing of the abdominal wall caused by pulling, oedema after a major operation (oncological operations). Acute postoperative dilation of the stomach; this is possible also after undergoing a gastrofibroscopic examination. [12]

Massive influx of fluids with forced volume therapy works on the abdominal wall in several ways. It leads to dilation of the veins in the area of the abdominal wall, becoming an oedema of the intestinal walls with increased pressure on the venous and lymphatic system with a resultant worsening of drainage. The stagnation of fluids in the intestinal wall endures with the development of tissue hypoxia. A vicous cycle begins; blood gets into the intestinal wall but does not reach the drainage of the venous system; the oedema grows. A decline in kidney function follows. According to recent studies close monitoring of the inflow and outflow of fluids is appropriate. $[6,7,12]$

\section{Treatment of ACS}

In clinical practice we have been coming across occurrences of ACS for a long time, and history has recorded data in which increased IAP in critically ill patients leads to a growth in morbidity and mortality. $[1,2,5,7]$

At present the occurrence of ACS is connected with repeated use of an old-new conception of treatment of serious traumatic injuries. In this strategy of treatment algorithm, a multi-stage procedure, described by different authors as Staged Laparotomy (Morris,1993), Planned Reoperation (Hisrhberg,1994), Abbreviated Laparotomy (Brenneman,1994) and Damage Control Laparotomy (Ivatury, 1997), is again fully acceptable. $[1,2,12]$

The essence of this approach is the carrying out of an immediate introductory laparotomy with necessary treatment of the organs and by stopping the lifeendangering bleeding. The aim is to anticipate the origin of irreversible coagulopathy, because coagulopathy worsened by hypothermia and acidosis is considered as a primary factor in the timely death of patients after a serious abdominal injury. [12] 


\section{Verification of Measuring System}

The testing device for verifying the pressure sensor consists of two parts (Fig. 3). In the first a model of the abdomen is made from a $250 \mathrm{ml}$ saline bag (in the place of the bladder). This saline bag is placed in the bottom of a $35 \mathrm{~L}$ container which allows pressure to be built up to $25 \mathrm{mmHg}$. Velcro is used to anchor the bag to the bottom of the container. $[8,10]$

For determining the impact of the anchoring of the model of the bladder two versions of the clamp were tested. In the first version, the bag for the saline was anchored with two Velcro fastener strips along its full length in the middle. Upon testing it was determined that the edges of the bag have a tendency to lift and thus shift the zero point for measurement. To prevent such lifting of the bag edges, Velcro strips were attached to the inside of the container and to the four corners of the bag (Figure 4). [8, 10, 11]

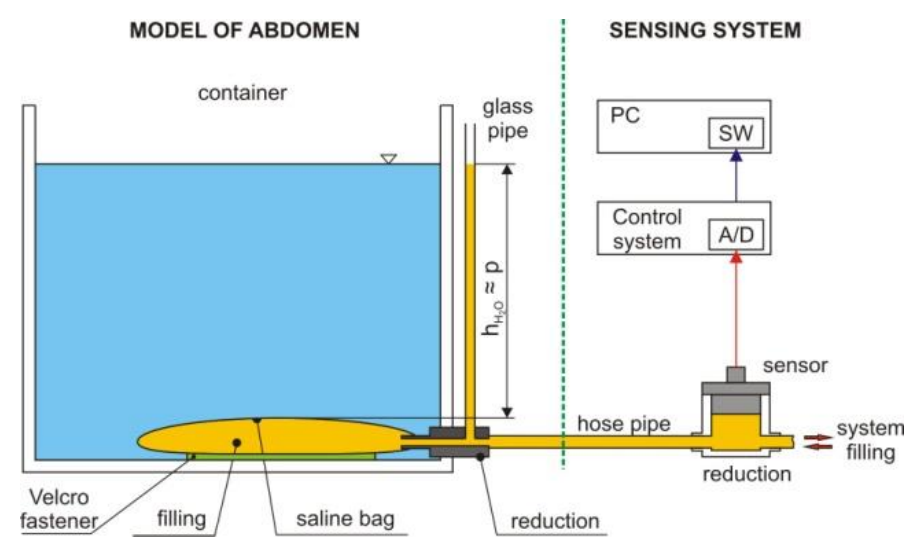

Figure 3

Schematic representation of sensing system $[8,10]$

The second part is the sensing system.

The selection of an inter-abdominal pressure sensor is subject to strict hygienic and safety conditions. Among the most basic are that it be possible to disinfect the sensor and that upon its being damaged no contamination of the measuring space can occur. $[8,10,11]$ 


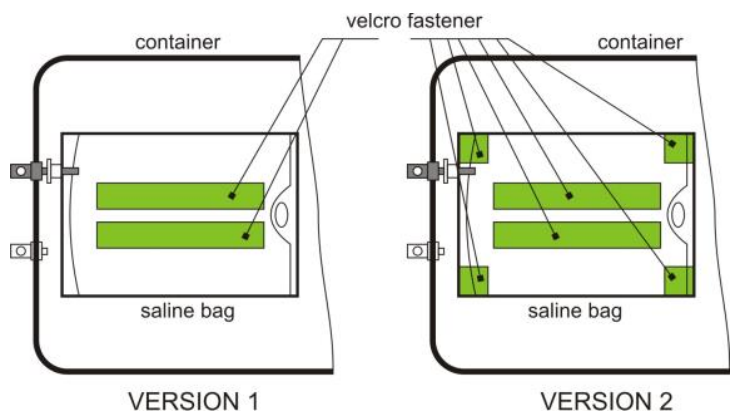

Figure 4

Versions of the clamp

On the basis of the given criteria the selected sensor was model number DMP 331 $\mathrm{P}$ from the company BD SENSORS. The sensor is also supplied in a variant filled with edible oil. The basic parameters of the sensor are presented in Table 2. [8]

The measuring range (0-0.1) bar corresponds to $10 \mathrm{kPa}$ or $75 \mathrm{mmHg}$, while 3.3 $\mathrm{kPa}$ or $25 \mathrm{mmHg}$ is desirable. The sensor, therefore, has sufficient reserve for measuring. The sensor has an output of $(0-5) \mathrm{V}$, thus it is possible to connect it directly into the microcontroller. [8]

Table 2

Basic parameter of DMP $331 \mathrm{P}$ sensor [8]

\begin{tabular}{|l|l|}
\hline & Value \\
\hline Measuring range $[$ bar $]$ & $0-0,1$ \\
\hline Accuracy & $0,5 \%$ from measuring range \\
\hline Output $[\mathrm{V}]$ & $0-5$ \\
\hline Cover & IP 65 \\
\hline Material of the sensor body & stainless steel \\
\hline Filling & edible oil \\
\hline
\end{tabular}

The sensing system is connected to a reduction through tubing of $4 \mathrm{~mm}$ inner diameter [10].

The measurement was performed as follows:

- the saline bag was filled with $100 \mathrm{ml}$ of water

- $5 \mathrm{mmHg}$ pressure was created through the water column, and the value was read from the level gauge,

- $\quad$ stabilization of the water level $(15-20) \mathrm{s}$,

- $\quad$ measuring process (Figure 5),

- increasing the pressure up to $25 \mathrm{mmHg}$ stepwise by $5 \mathrm{mmHg}$ per step, measuring after each increment, 
- decreasing the pressure after reaching $25 \mathrm{mmHg}$ stepwise by $5 \mathrm{mmHg}$ steps, measuring after each decrement,

- 20 measurement packs were obtained with this approach, and each pack contained 5 levels of measurement $(5-25 \mathrm{mmHg}$ with $5 \mathrm{mmHg}$ steps $)$ (Figure 5) (Table 3) (Table 4) [9, 10].

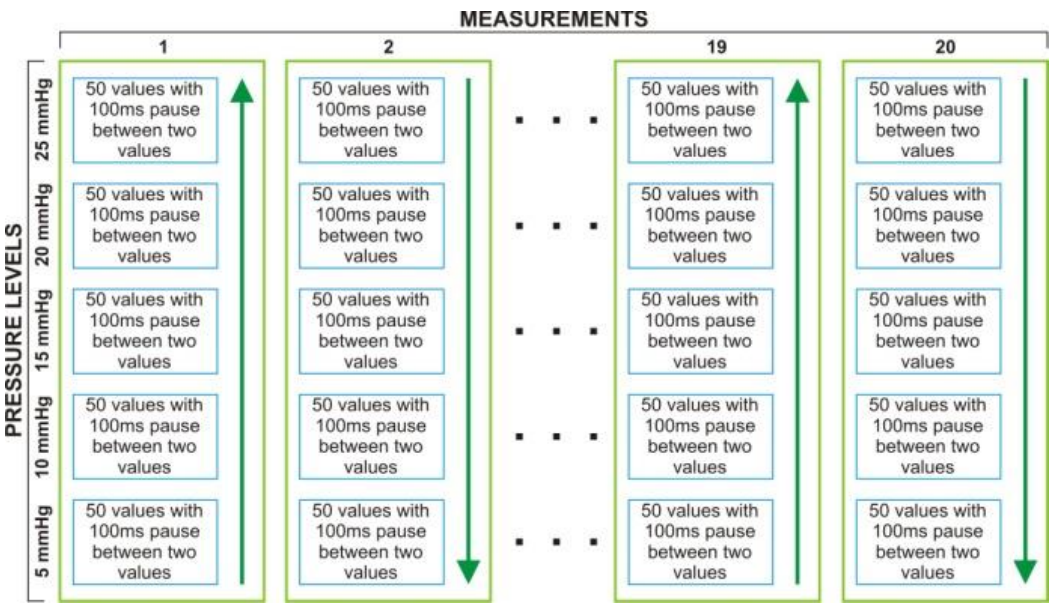

Figure 5

Schematic representation of measuring process $[9,10]$

Each measurement contains 50 values with $100 \mathrm{~ms}$ pause between two values. The pressure sensor has an analog output $(0-5 \mathrm{~V})$, which is processed in a PIC microprocessor. The program in the PIC was designed to read data from the sensor, perform the A/D conversion (10-bit) and then send the data to a PC. [8, 10]

The outcome consists of data in a range from 0 to 1023, which represents the total range of the sensor $(0-75) \mathrm{mmHg}$ or $(0-0.1)$ bar. These are subsequently converted to a pressure value through the relation [8]

$p_{B D}=$ measured_value $\cdot \frac{75}{1023}[\mathrm{mmHg}]$

The surface tension of the water in the container is reduced by adding washing up liquid, which allows for a more exact filling of the container to the desired level. $[8,10]$ 
Table 3

Table of the recalculated pressure values for version $1[8,10]$

\begin{tabular}{|l|l|l|l|l|l|}
\hline \multirow{2}{*}{$\mathrm{i}$} & \multicolumn{5}{|c|}{ Pressure $[\mathrm{mm} \mathrm{Hg}]$} \\
\cline { 2 - 6 } & $p(5)_{i}$ & $p(10)_{i}$ & $p(15)_{i}$ & $p(20)_{i}$ & $p(25)_{i}$ \\
\hline 1 & 5,413 & 10,326 & 15,180 & 20,084 & 24,889 \\
\hline 2 & 5,368 & 10,194 & 15,072 & 19,870 & 24,834 \\
\hline 3 & 5,408 & 10,267 & 15,154 & 19,950 & 24,845 \\
\hline 4 & 5,377 & 10,232 & 15,113 & 19,978 & 24,821 \\
\hline 5 & 5,411 & 10,284 & 15,157 & 20,001 & 24,840 \\
\hline 6 & 5,430 & 10,249 & 15,114 & 19,944 & 24,886 \\
\hline 7 & 5,430 & 10,273 & 15,255 & 19,985 & 24,817 \\
\hline 8 & 5,403 & 10,214 & 15,075 & 19,911 & 24,837 \\
\hline 9 & 5,368 & 10,267 & 15,075 & 19,933 & 24,817 \\
\hline 10 & 5,443 & 10,236 & 15,092 & 19,762 & 24,824 \\
\hline 11 & 5,422 & 10,271 & 15,114 & 19,982 & 24,804 \\
\hline 12 & 5,421 & 10,226 & 15,041 & 19,889 & 24,839 \\
\hline 13 & 5,361 & 10,227 & 15,095 & 19,960 & 24,786 \\
\hline 14 & 5,371 & 10,254 & 15,051 & 19,905 & 24,826 \\
\hline 15 & 5,431 & 10,249 & 15,063 & 19,971 & 24,783 \\
\hline 16 & 5,491 & 10,309 & 15,097 & 19,997 & 24,905 \\
\hline 17 & 5,504 & 10,352 & 15,166 & 20,006 & 24,853 \\
\hline 18 & 5,415 & 10,283 & 15,107 & 20,026 & 24,865 \\
\hline 19 & 5,472 & 10,279 & 15,157 & 20,015 & 24,837 \\
\hline 20 & 5,443 & 10,315 & 15,135 & 20,006 & 24,861 \\
\hline Mean $\bar{p}$ & 5,419 & 10,265 & 15,116 & 19,959 & 24,838 \\
\hline Standard deviation $s_{p}$ & 0,040 & 0,040 & 0,052 & 0,069 & 0,032 \\
\hline $\bar{p}+3 s_{p}$ & 5,538 & 10,384 & 15,270 & 20,166 & 24,934 \\
\hline $\bar{p}-3 s_{p}$ & 5,300 & 10,146 & 14,961 & 19,752 & 24,743 \\
\hline
\end{tabular}

The values from the A/D converter are recalculated to a pressure value (Table 3, Figure 6). Data evaluation was performed in Microsoft Excel 2003. [8, 10]

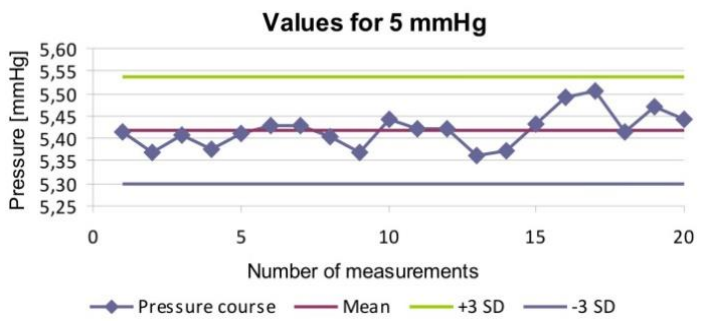

Figure 6

Trend for $5 \mathrm{mmHg}, \mathrm{SD}$ - standard deviation $[8,10]$ 
The dependency of the measured values on the expected values is linear (Fig. 7), with a correlation coefficient from 0.98 to 1 . $[8,10]$

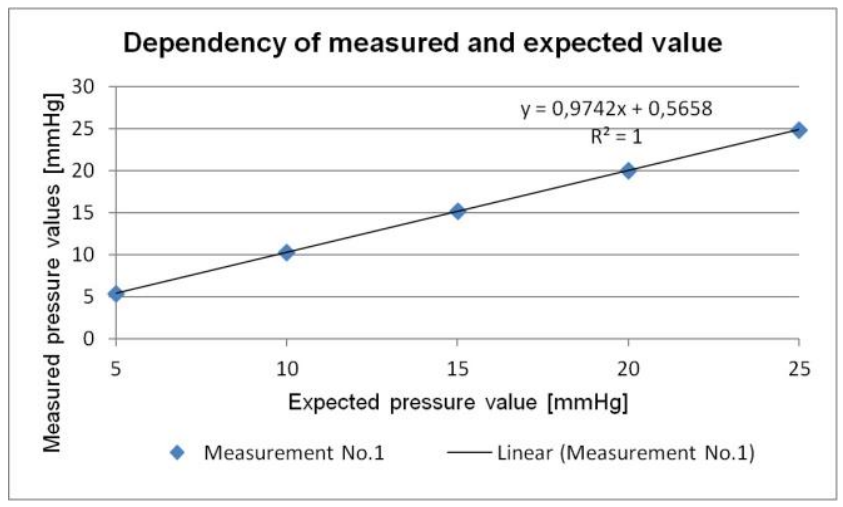

Figure 7

Dependency of the measured values on the expected values

Differences in the measured values upon comparison of both variants for solving the anchoring of the bag of saline solution are greater than $0.5 \mathrm{mmHg}$ for each range. (Table 4, Table 5)

Table 4

Table of the recalculated pressure values for version $2[8,10]$

\begin{tabular}{|l|l|l|l|l|l|}
\hline \multirow{2}{*}{$\mathrm{i}$} & \multicolumn{5}{|c|}{ Pressure $[\mathrm{mmH}]$} \\
\hline 1 & $p(5)_{i}$ & $p(10)_{i}$ & $p(15)_{i}$ & $p(20)_{i}$ & $p(25)_{i}$ \\
\hline 2 & 4,799 & 9,713 & 14,472 & 19,274 & 24,258 \\
\hline 3 & 4,799 & 9,809 & 14,414 & 19,403 & 23,965 \\
\hline 4 & 4,826 & 9,638 & 14,367 & 19,346 & 23,978 \\
\hline 5 & 4,821 & 9,701 & 14,522 & 19,518 & 23,993 \\
\hline 6 & 4,771 & 9,463 & 14,430 & 19,304 & 24,000 \\
\hline 7 & 4,786 & 9,691 & 14,589 & 19,424 & 23,930 \\
\hline 8 & 4,837 & 9,521 & 14,422 & 19,334 & 23,936 \\
\hline 9 & 4,805 & 9,691 & 14,518 & 19,397 & 24,006 \\
\hline 10 & 4,779 & 9,641 & 14,434 & 19,333 & 24,021 \\
\hline 11 & 4,779 & 9,645 & 14,469 & 19,384 & 23,877 \\
\hline 12 & 4,757 & 9,570 & 14,346 & 19,264 & 23,874 \\
\hline 13 & 4,736 & 9,658 & 14,431 & 19,204 & 23,963 \\
\hline 14 & 4,691 & 9,567 & 14,447 & 19,315 & 23,930 \\
\hline 15 & 4,716 & 9,638 & 14,427 & 19,367 & 24,028 \\
\hline 16 & 4,701 & 9,644 & 14,458 & 19,321 & 24,019 \\
\hline 17 & 4,680 & 9,560 & 14,446 & 19,292 & 23,977 \\
\hline & 4,685 & 9,685 & 14,475 & 19,296 & 23,950 \\
\hline & & & & & \\
\hline & & 4,63 &
\end{tabular}




\begin{tabular}{|l|l|l|l|l|l|}
\hline 18 & 4,676 & 9,616 & 14,378 & 19,219 & 23,897 \\
\hline 19 & 4,691 & 9,543 & 14,386 & 19,267 & 23,908 \\
\hline 20 & 4,692 & 9,632 & 14,302 & 19,368 & 23,924 \\
\hline Average $\bar{p}$ & 4,751 & 9,631 & 14,437 & 19,332 & 23,972 \\
\hline Standard deviation $s_{p}$ & 0,055 & 0,078 & 0,065 & 0,074 & 0,082 \\
\hline $\bar{p}+3 s_{p}$ & 4,918 & 9,865 & 14,631 & 19,553 & 24,218 \\
\hline $\bar{p}-3 s_{p}$ & 4,585 & 9,397 & 14,242 & 19,110 & 23,725 \\
\hline
\end{tabular}

The following table (Table 5), which determines the difference of a nominal (reference) value versus a measured value, serves for determining the better variant.

Table 5

Pressure differences between two variants

\begin{tabular}{|l|l|l|l|l|l|}
\hline \multirow{2}{*}{$\mathrm{i}$} & \multicolumn{5}{|c|}{ Pressure $[\mathrm{mmH}]$} \\
\cline { 2 - 6 } & $p(5)_{i}$ & $p(10)_{i}$ & $p(15)_{i}$ & $p(20)_{i}$ & $p(25)_{i}$ \\
\hline 1 & 0,6139 & 0,6134 & 0,7079 & 0,8098 & 0,6309 \\
\hline 2 & 0,5689 & 0,3846 & 0,6585 & 0,4668 & 0,8692 \\
\hline 3 & 0,5825 & 0,6292 & 0,7874 & 0,604 & 0,867 \\
\hline 4 & 0,5559 & 0,5311 & 0,591 & 0,4604 & 0,8283 \\
\hline 5 & 0,6397 & 0,8207 & 0,7274 & 0,6975 & 0,84 \\
\hline 6 & 0,6441 & 0,5584 & 0,5246 & 0,5202 & 0,9564 \\
\hline 7 & 0,5928 & 0,7525 & 0,8327 & 0,6507 & 0,8815 \\
\hline 8 & 0,598 & 0,5234 & 0,5574 & 0,5136 & 0,8311 \\
\hline 9 & 0,5894 & 0,6262 & 0,641 & 0,6002 & 0,7965 \\
\hline 10 & 0,6644 & 0,5908 & 0,6228 & 0,3778 & 0,9472 \\
\hline 11 & 0,6654 & 0,7006 & 0,768 & 0,7181 & 0,9301 \\
\hline 12 & 0,6849 & 0,5676 & 0,6099 & 0,6852 & 0,8757 \\
\hline 13 & 0,6704 & 0,6596 & 0,6478 & 0,6448 & 0,8564 \\
\hline 14 & 0,6555 & 0,6162 & 0,6243 & 0,5384 & 0,7981 \\
\hline 15 & 0,7301 & 0,6053 & 0,6055 & 0,6499 & 0,7639 \\
\hline 16 & 0,8106 & 0,7489 & 0,6513 & 0,7052 & 0,9285 \\
\hline 17 & 0,8192 & 0,6672 & 0,6909 & 0,7098 & 0,9029 \\
\hline 18 & 0,739 & 0,6672 & 0,7287 & 0,8075 & 0,9676 \\
\hline 19 & 0,7814 & 0,7365 & 0,7714 & 0,7481 & 0,9294 \\
\hline 20 & 0,7509 & 0,683 & 0,8329 & 0,638 & 0,9372 \\
\hline Mean & 0,6678 & 0,6341 & 0,6790 & 0,627 & 0,86689 \\
\hline Standard deviation $s_{p}$ & 0,0804 & 0,0975 & 0,0881 & 0,1171 & 0,0803 \\
\hline & & & & & \\
\hline
\end{tabular}

The individual values are calculated as follows:

Deviation 1 = Absolute value (nominal value - value of "version 1"). 
Total deviation for the selected version $=$ the sum of all deviations for selected version. (Table 6), (Figure 8)

Table 6

Calculation of fifferences between two variants

\begin{tabular}{|c|c|c|c|c|}
\hline Nominal Value & Version 1 & Version 2 & Deviation 1 & Deviation 2 \\
\hline 5 & 5,419 & 4,751 & 0,419 & 0,249 \\
\hline 10 & 10,265 & 9,631 & 0,265 & 0,369 \\
\hline 15 & 15,116 & 14,437 & 0,116 & 0,563 \\
\hline 20 & 19,959 & 19,332 & 0,041 & 0,669 \\
\hline 25 & 24,838 & 23,972 & 0,162 & 1,028 \\
\hline \multicolumn{3}{|l|}{ Total deviation } & 1,003 & 2,8779 \\
\hline
\end{tabular}

From the results it is obvious that the total deviation for Variant 2 is nearly 3times the total deviation for Variant 1 . Fom this it follows that anchoring the bag of saline solution using Variant 1 is more suitable.

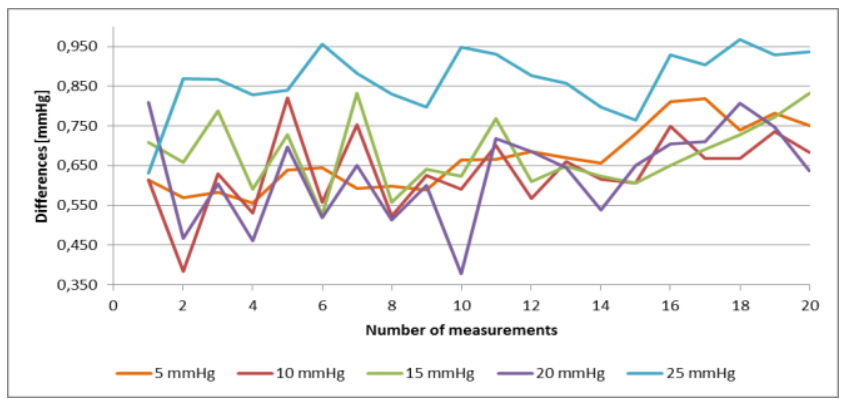

Figure 8

Values for differences between two variants

\subsection{Measurement Error Determination}

The total error measurement is given by the error of the sensor and the error of the converter.

The error of the sensor is given by the manufacturer and represents $0.5 \%$ of the measuring range, which is, to the extent required, a precision of measuring to a whole number; the sensor also satisfies this condition. [8]

$\varepsilon_{s}=\frac{\text { sensor_range }}{100}$. sensor_error $=\frac{10000 \mathrm{~Pa}}{100} \cdot 0,5=50 \mathrm{~Pa} \quad$ resp. $\quad 0,375 \mathrm{mmHg}$

For digitalisation of the pressure from the sensor, an integrated 10-bit converter is used. [8] 
The sensitivty of the converter $L S B$ (Least Significant Bit) can be calculated from the relation:

$$
L S B=\frac{F S}{2^{n}}=\frac{5 \mathrm{~V}}{2^{10}}=0,00488 \mathrm{~V}
$$

where $F S$ (Full Scale) is the range of the converter and $\mathrm{n}$ is the number of bits.

A quantization error represents the theoretical maximum difference between the value of the analogue parameter and its maximum value corresponding to the given code word; it is given by the relation:

$$
Q E=\frac{L S B}{2}=\frac{0,00488 \mathrm{~V}}{2}=0,00244 \mathrm{~V}
$$

The accuracy of the pressure measurement for a measuring a range of 0.1 bar, i.e. 75 tors, can be calculated from the relation:

$$
\frac{L S B}{F S} \text {.sensor_range }=\frac{0,00488 \mathrm{~V}}{5 \mathrm{~V}} .75 \mathrm{mmHg}=0,0732 \mathrm{mmHg}
$$

If a sensor error reaches the maximum allowable value and at the same time a quantization error is also expressed, then there is a total error of measurement:

$$
\begin{gathered}
\varepsilon=\varepsilon_{s}+\varepsilon_{p}=\varepsilon_{s}+\frac{Q E}{F S} \text {.sensor_range }= \\
=0,375 \mathrm{mmHg}+\frac{0,00244 \mathrm{~V}}{5 \mathrm{~V}} .75 \mathrm{mmHg}=0,41 \mathrm{mmHg} \text { resp. } 54,66 \mathrm{~Pa}
\end{gathered}
$$

Because intra-abdominal pressure is measured for an entire unit, this error is below the margin of acceptability. Its value can be lowered by use of a converter with higher resolution capability. The total error of measurement for a 16-bit converter is on the level of the sensor error. [8]

$$
\begin{gathered}
\varepsilon=\varepsilon_{s}+\varepsilon_{p}=\varepsilon_{s}+\frac{\frac{1}{2} \frac{F S}{2^{n}}}{F S} \text {.sensor_range }= \\
=0,375 \mathrm{mmHg}+\frac{\frac{1}{2} \frac{5 \mathrm{~V}}{2^{16}}}{5 \mathrm{~V}} .75 \mathrm{mmHg}=0,376 \mathrm{mmHg} \quad \text { resp. } 50,13 \mathrm{~Pa}
\end{gathered}
$$

\section{Conclusion}

A proposed measuring device for medical applications must satisfy the appropriate conditions for safety and for reliable use. The sterilisation of all parts which come into contact with body fluids (urine) is one of these conditions. This condition has a basic effect during sensor selection. 
In the course of testing the system's sensor two methods of anchoring the bag for saline solution were verified. The methodology for testing was the same in both cases. In view of the principles of the measurement (measuring with a column of water) it was necessary to measure under stable weather conditions, because a change in atmospheric pressure can influence the measured values. The difference between the two methods of anchoring for pressures of $5-20 \mathrm{mmHg}$ is approximately $0.65 \mathrm{mmHg}$ and for a range of $25 \mathrm{mmHg}$ it is approximately 0.87 $\mathrm{mmHg}$. Because when measuring internal-abdominal pressure measuring in units of $\mathrm{mmHg}$ is sufficient, the measuring of intra-abdominal pressure is within the tolerance limits for both Variants. From an evaluation of the results, it follows that measuring using Variant 1 is more precise.

The total error of the sensing system is on a level of $0.41 \mathrm{mmHg}$. For decreasing the total error of measurement it is possible to use a stand-alone 16-bit A/D converter. The total error in this case will be equal to the sensor error.

\section{Acknowledgement}

This contribution is the result of the project implementation: Center for research of control of technical, environmental and human risks for permanent development of production and products in mechanical engineering (ITMS:26220 120060) supported by the Research \& Development Operational Programme fund ed by the ERDF.

\section{References}

[1] Malbrain, ML., Cheatham, ML., Kirkpatrick, A., Sugrue, M., Parr, M., De Waele, J., Balogh, Z., Leppäniemi, A., Olvera, C., Ivatury, R., D'Amours, S., Wendon, J., Hillman, K., Johansson, K., Kolkman, K., Wilmer, A.: Results from the International Conference of Experts on Intra-abdominal Hypertension and Abdominal Compartment Syndrome. I. Definitions, Intensive Care Med. 2006 Nov; 32(11):1722-32. Epub 2006 Sep 12

[2] Malbrain, ML., Cheatham, ML., Kirkpatrick, A., Sugrue, M., Parr, M., De Waele, J., Balogh, Z., Leppäniemi, A., Olvera, C., Ivatury, R., D'Amours, S., Wendon, J., Hillman, K., Wilmer, A.: Results from the International Conference of Experts on Intra-abdominal Hypertension and Abdominal Compartment Syndrome. II. Recommendations. Intensive Care Med. 2007 Jun; 33(6):951-62. Epub 2007 Mar 22

[3] Malbrain, ML., Deeren DH.: Effect of Bladder Volume on Measured Intravesical Pressure: a Prospective Cohort Study, Critical Care 2006, 10:R98, http://ccforum.com/content/10/4/R98

[4] Efstathiou, E., Zaka, M., et al.: "Intra-Abdominal Pressure Monitoring in Septic Patients." Intensive Care Medicine 31, 2005, Supplement 1(131): S183, Abstract 703

[5] Kinball, EJ.: IAP Measurement: Bladder Techniques, WCACS,, Antwerp, 2007 
[6] Malbrain ML, Cheatham ML, Kirkpatrick A, Sugrue M, De Waele J, Ivatury R.: Abdominal Compartment Syndrome: it's Time to Pay Attention!, Intensive Care Medicine, Volume 32, Number 11, November 2006, pp. 1912-1914(3)

[7] Ivatury, R., Cheatham M., Malbrain, M., Sugrue, M.: Abdominal Compartment Syndrome, Landes Biosciences, ISBN 978-1-58706-196-7

[8] Toth, T.: Návrh zariadenia na meranie intra - abdominálneho tlaku, Doktorandská dizertačná práca, Košice, 2009

[9] Tóth, T., Michalíková, M., Bednarčíková, L., Petrík, M., Živčák, J.: Verification of Measuring System for Automation Intra - Abdominal Pressure Measurement, In: MEDICON 2010 : 12 Mediterranean Conference on Medical and Biological Engineering and Computing 2010 : May 27-30. 2010, Chalkidiki, Greece. - s.l. : Springer, 2010 P. 513-516. ISBN 978-3-642-13038-0

[10] Tóth, T., Živčák, J., Liberko, I.: Verification of Measuring System for Intra - Abdominal Pressure Measurement, SAMI 2010, $8^{\text {th }}$ International Symposium on Applied Machine Intelligence and Informatics, January 2830, 2010, Herl'any, Slovakia, pp. 297-299, ISBN 978-1-4244-6423-4

[11] Tóth, T., Michalíková, M., Tkáčová, M., Živčák, J.: Overenie snímacieho systému na meranie intra-abdominálneho tlaku, Trendy v biomedicínském inženýrství: 21. - 23.zář́í, 2011, Rožnov pod Radhoštěm. - Ostrava, pp. 134-137, ISBN 978-80-248-2479-6

[12] Liberko, I.: Neinvazívne meranie vnútrobrušného tlaku pri kompartment syndróme brušnej dutiny : doktorandská dizertačná práca Košice, 2010 